\title{
CARACTERIZAÇÃO FÍSICA E QUÍMICA DE FRUTOS DE MARACUJAZEIRO-AMARELO ENXERTADO EM ESPÉCIES SILVESTRES DO GÊNERO PASSIFLORA CULTIVADO EM AMBIENTE PROTEGIDO ${ }^{1}$
}

\author{
ALEJANDRO HURTADO-SALAZAR ${ }^{2}$, DANIELLE FABIOLA PEREIRA DA SILVA ${ }^{3}$, \\ CARLOS SIGUEYUKI SEDIYAMA ${ }^{4}$, CLAUDIO HORST BRUCKNER ${ }^{4}$
}

RESUMO- O mercado de frutas frescas do maracujá-amarelo valoriza as qualidades interna e externa dos frutos. O uso de espécies silvestres como porta-enxertos tem sido preconizado como possível medida de controle de doenças. São escassas as informações sobre o efeito de espécies silvestres do gênero Passiflora como porta-enxertos sobre as características físicas e químicas em frutos de maracujazeiro. O objetivo deste trabalho foi determinar a influência de duas espécies de passifloráceas silvestres $P$. mucronata Lam e $P$. gibertii N.E. Brow como porta-enxertos sobre as características físicas e químicas dos frutos do maracujazeiro-amarelo em ambiente protegido. Adotou-se o delineamento inteiramente casualizado, com quatro tratamentos e 25 repetições, consistindo em 100 parcelas. Cada parcela foi representada por uma planta conduzida em vaso de 30 L. Os porta-enxertos avaliados foram: Passiflora edulis Sims, Passiflora gibertii N.E. Brow e Passiflora mucronata Lam. Como tratamento-testemunha, foram utilizadas plantas de P. edulis Sims provenientes de sementes. Avaliaram-se a massa fresca do fruto (MF), a massa fresca da casca (MC), a massa fresca da polpa (MP), o diâmetro do fruto (DF), o comprimento longitudinal do fruto (CF), a espessura da casca dos frutos (EC), a coloração do suco e da casca dos frutos, o teor de sólidos solúveis (SS), a acidez titulável (AT), a relação SS/AT, a relação MP/MF e o teor de vitamina C (ácido ascórbico). As plantas enxertadas sobre espécies silvestres produziram frutos mais alongados que as plantas provenientes de sementes, porém dentro dos padrões de comercialização.

Termos para indexação: Porta-enxertos, maracujá-amarelo, qualidades físicas e químicas dos frutos.

\section{PHYSICAL AND CHEMICAL CHARACTERIZATION OF YELLOW PASSION FRUIT GRAFTED ONTO WILD SPECIES OF GENUS PASSIFLORA CULTIVATED IN GREENHOUSE}

\begin{abstract}
The market for fresh fruits passion fruit enhances internal and external fruit quality. The use of wild species as rootstocks has been advocated as a possible measure of disease control. Information are scarce on the effect of wild species of the genus Passiflora as rootstocks on physical and chemical characteristics in passion fruits. The objective of this study was to determine the influence of two species of wild passifloraceae, P. mucronata Lam and P. gibertii NE Brow as rootstocks on physical and chemical characteristics of yellow passion fruit in greenhouse. We adopted a completely randomized design with four replications and 25 treatments, consisting of 100 plots. Each plot was represented by a plant conducted in a pot of 30 L. The rootstocks were: Passiflora edulis Sims, Passiflora gibertii NE Brown and Passiflora mucronata Lam. As the control treatment, plants of P. edulis Sims originated from seeds were used. Evaluations of fresh fruit mass (FM), peel fresh weight (PeW), pulp fresh weight (PuW), fruit diameter (FD), longitudinal length of the fruit (LLF), thickness of the fruit skin (TFS), the color of the juice and the fruit peel, soluble solids (SS), titratable acidity (TA), ratio SS/TA, ratio PuW/PeW, vitamin C (ascorbic acid) content. Plants grafted on wild species produced more elongated fruit plants originated from seeds, but within the commercialization standards.

Index terms: Rootstock, passion fruit, physical and chemical quality of the fruit.
\end{abstract}

\footnotetext{
${ }^{1}$ (Trabalho 101-14). Recebido em: 27-03-2014. Aceito para publicação em : 27-04-2015

${ }^{2}$ Eng. Agr ${ }^{\circ}$, Doutorando do Depto. de Fitotecnia, UFV, Viçosa - MG. E-mail: alhuza@gmail.com

${ }^{3}$ Eng. Agra , Dr. Pos-doutoranda do Depto. de Fitotecnia, UFV, Viçosa-MG. E-mail: danieele@ufv.br

${ }^{4}$ Eng. Agr ${ }^{\circ}$, Dr. Professor do Depto. de Fitotecnia, UFV, Viçosa - MG. E-mails: bruckner@ufv.br; csediyama@ufv.br
} 


\section{INTRODUÇÃO}

A aparência é o critério mais utilizado pelos consumidores para avaliar a qualidade dos frutos (KRAUSE et al., 2012). Uma fruta de qualidade é aquela que atende às expectativas dos diferentes segmentos consumidores, em suas características internas e externas. As internas e externas: sendo as internas relacionadas ao sabor (sólidos solúveis e acidez) e conteúdo de suco (rendimento), e as externas relacionadas a uma boa aparência (cor da casca, tamanho, peso, ausência de defeitos dos frutos), atendendo a certos padrões para que atinjam a qualidade desejada nos mercados, permitindo identificar acessos-elites com frutas de alta qualidade (OCAMPO et al., 2013).

A enxertia é amplamente utilizada na fruticultura e em outras espécies perenes com os objetivos de propagar genótipos superiores, controlar porte de plantas, reduzir período juvenil, adaptar a planta a condições adversas de solos e oferecer resistência a pragas e doenças (ATUCHA et al., 2014; MACHADO et al., 2013). Na cultura do maracujazeiro-amarelo, a resistência de algumas espécies silvestres como: Passiflora suberosa, $P$. alata, $P$. coccinea, $P$. gibertii e P. Setace, a morte prematura de plantas foi relatada por Silva et al. (2013). Cavichioli et al. (2011) avaliaram o efeito do porta-enxerto e do tipo de enxertia sobre a qualidade dos frutos de maracujazeiro-amarelo, encontrando que os porta-enxertos utilizados ( $P$. edulis, $P$. alata e $P$. gibertii) não influenciaram no teor de SS, na AT e em sua relação SS/AT. Igualmente, o método de enxertia não interferiu no diâmetro, no comprimento, na massa fresca dos frutos, na massa e na espessura da casca, no rendimento do suco e no teor de SST. Contudo, são escassas as informações sobre o efeito de espécies silvestres de passifloráceas como porta-enxerto para o maracujazeiro-amarelo e suas influências sobre as características físicas e químicas em frutos de maracujazeiro. Assim, o objetivo deste trabalho foi determinar a influência de espécies silvestres de passifloráceas como porta-enxerto para o maracujazeiro-amarelo e seus efeitos sobre a aqualidade de seus frutos em ambiente protegido.

\section{MATERIAL E MÉTODOS}

$\mathrm{O}$ experimento foi realizado em ambiente protegido com cobertura de polietileno de baixa densidade, com espessura de $150 \mu \mathrm{m}$ e telado para estufa de cítrus antiafídeo nas laterais, no setor de
Fruticultura da Universidade Federal de Viçosa (UFV), Viçosa-MG, que se encontra a $651 \mathrm{~m}$ de altitude, na latitude sul $20^{\circ} 45^{\prime} 20^{\prime \prime}$ e na longitude oeste $42^{\circ} 52^{\prime} 40^{\prime \prime}$, com clima tipo Cwa, mesotérmico úmido, com verões chuvosos e invernos secos (MATARAZZO et al., 2013), no período de outubro/2011 a dezembro/2012.

Adotou-se o delineamento inteiramente casualizado, com quatro tratamentos e 25 repetições, perfazendo um total de 100 parcelas. Cada parcela foi representada por uma planta conduzida em vaso de $30 \mathrm{~L}$. Os porta-enxertos avaliados foram: Passiflora edulis Sims, Passiflora gibertii N.E. Brow e Passiflora mucronata Lam. Como tratamentostestemunha, foram utilizadas plantas de $P$. edulis provenientes de sementes e enxertadas sobre a mesma espécie.

Para a produção de plantas utilizadas como porta-enxertos, as sementes de $P$. edulis, $P$. gibertii e $P$. mucronata foram obtidas da coleção de passifloráceas do setor de Fruticultura da Universidade Federal de Viçosa (UFV), ViçosaMG, assim como aquelas utilizadas para a produção dos garfos para a enxertia. A produção das mudas foi feita realizando-se a germinação das sementes em areia lavada, em caixas plásticas de $40 \mathrm{~cm}$ de largura x $20 \mathrm{~cm}$ de altura x $50 \mathrm{~cm}$ de comprimento. Após a completa expansão da folha cotiledonar, 150 plântulas de cada espécie foram transplantadas para sacos plásticos de $10 \mathrm{~cm} \times 23 \mathrm{~cm}$. Aos 60 dias após a semeadura, realizou-se a enxertia do tipo fenda cheia a $10 \mathrm{~cm}$ do colo da planta. Os garfos, com dois nós, foram retirados na porção mediana dos ramos de cinco plantas adultas de maracujazeiro-amarelo. Com as primeiras brotações do enxerto, as plantas foram transplantadas aos quatro meses de idade para vasos de $30 \mathrm{~L}$, na casa de vegetação.

O substrato foi constituído de mistura de terra, areia e esterco, na proporção $3: 1: 1$, corrigido de acordo com a análise do solo quanto à acidez $(100$ g de calcário/vaso de $30 \mathrm{~L}$ ), e com adubação de $300 \mathrm{~g}$ de superfosfato simples. As plantas foram conduzidas em haste única e tutoradas com auxílio de cordão até fio de aço localizado a $2 \mathrm{~m}$ de altura. As podas dos ramos laterais (desbrotas) foram feitas a cada 15 dias ou de acordo com o desenvolvimento da planta.

Quando as plantas atingiram $15 \mathrm{~cm}$ de altura, 60 dias após a enxertia, realizou-se a primeira adubação com o equivalente a $5 \mathrm{~g}$ de sulfato de amônio e $10 \mathrm{~g}$ de cloreto de potássio; trinta dias após, foi realizada a segunda adubação, fornecendo o equivalente a $10 \mathrm{~g}$ de sulfato de amônio e $15 \mathrm{~g}$ de 
cloreto de potássio, perfazendo um total de $15 \mathrm{~g}$ de $\mathrm{N} \mathrm{e} 20$ de $\mathrm{P}_{2} \mathrm{O}_{5}$, sabendo que o sulfato de amônio e o cloreto de potássio contêm, aproximadamente, $20 \%$ de $\mathrm{Ne} 60 \% \mathrm{~K}_{2} \mathrm{O}$. Foi necessário fazer adubação com $21 \mathrm{~g}$ de sulfato de magnésio diluído em $1 \mathrm{~L}$ de água por planta e $13 \mathrm{~g}$ de gesso agrícola em cobertura, após 60 dias do transplante, a cada 30 dias até 250 dias. Também, fez-se necessária a aplicação de acaricida abamectina (18 g i. a. / L), após 60 dias de transplante. A condução foi realizada conforme os tratos culturais recomendados para a cultura.

Utilizou-se do sistema de irrigação por gotejamento, onde a linha de irrigação possuía em cada vaso dois gotejadores com vazões de $0.5-5 \mathrm{~L}$ $\mathrm{h}^{-1}$ dispostos ao redor da planta, sendo, estas irrigadas diariamente com $1 \mathrm{~L} \mathrm{~h}^{-1}$ por planta.

Para avaliar as características físicas e químicas dos frutos, foram polinizadas 172 flores em cada planta. A polinização artificial foi realizada manualmente, entre 14 e $17 \mathrm{~h}$, sempre que havia flores abertas, entre agosto e dezembro de 2012, até obter uma média de 10 frutos por planta, sendo portanto, colhidos e avaliados 10 frutos por parcela para as análises. e químicas:

Foram realizadas as seguintes análises físicas

a) Massa fresca do fruto (MF) - os frutos foram pesados individualmente com auxílio de balança digital $(\mathrm{g})$, sendo a massa média obtida pela razão da massa total dos frutos do tratamento, pelo número total de frutos do tratamento.

b) Massa fresca média da casca (MC) - os frutos foram pesados individualmente com auxílio de balança digital (g), sendo a massa média obtida pela razão da massa total da casca dos frutos do tratamento, pelo número total desses.

c) Massa fresca da polpa (MP) - a polpa de cada fruto foi pesada individualmente com auxílio de balança digital $(\mathrm{g})$, sendo a massa média obtida pela razão da massa total da polpa dos frutos do tratamento, pelo número total desses.

d) Diâmetro médio do fruto (DF) - foi feito através de medição dos frutos na região equatorial com o uso de paquímetro digital, e a leitura, expressa em milímetros (mm). O comprimento longitudinal médio do fruto $(\mathrm{CF})$ foi obtido pela medição dos frutos, medindo-se o eixo longitudinal de cada um com o uso de paquímetro $(\mathrm{mm})$.

e) Espessura média da casca (EC)- foi feita na porção mediana dos frutos cortados ao meio com o auxílio de paquímetro digital ( $\mathrm{mm}$ ).

f) Coloração do suco e da casca dos frutos- foi analisada com colorímetro MINOLTA CR-10, com base nos valores de L, C (a, b) e $\mathrm{h}^{\mathrm{o}}$, em que $\mathrm{L}$ indica a luminosidade $(0=$ preto e $100=$ branco $)$ e a e $b$ representam as coordenadas de cromaticidade $(+\mathrm{a}=$ vermelho; $-\mathrm{a}=$ verde; $+\mathrm{b}=$ amarelo; e $-\mathrm{b}=\mathrm{azul})$. Esses valores foram convertidos em ângulo de cor, $\lambda^{\circ}=$ tan- $1 \mathrm{~b} / \mathrm{a}$, indicando o ângulo Hue $\left(\lambda^{\circ}\right)$ da amostra $\left(0^{\circ}\right.$ ou $360^{\circ}=$ vermelho $; 90^{\circ}=$ amarelo; $180^{\circ}=$ verde; e $270^{\circ}=$ azul) (SILVA et al., 2014).

Para determinar a coloração da casca, foram feitas duas leituras em faces opostas de cada fruto. Já para definir a coloração do suco, ele foi previamente extraído e coado em béquer de $100 \mathrm{~mL}$, onde se fez a leitura com aparelho a $1 \mathrm{~cm}$ da superfície do suco.

g) O teor de sólidos solúveis (SS) - foi determinado com três gotas do suco, após a extração, com auxílio de refratômetro digital.

h) A acidez titulável-foi determinada com suco de frutos individuais, obtida através de $5 \mathrm{~mL}$ do suco e transferidos para erlenmeyers de $250 \mathrm{~mL}$, completando-se o volume para $100 \mathrm{~mL}$ com água destilada. Foram adicionadas a essa solução três gotas de indicador fenolftaleína a $1 \%$, procedendo-se às titulações, sob agitação, com solução de $\mathrm{NaOH} 0,1 \mathrm{~N}$, previamente padronizada com biftalato de potássio. Os resultados foram expressos em $\mathrm{g}$ de ácido cítrico por $100 \mathrm{~g}$ de polpa.

A relação teor de sólidos solúveis/acidez titulável foi obtida por meio do quociente entre as duas características.

Obteve-se a relação massa da polpa/massa do fruto por meio do quociente entre as duas características.

i) O teor de vitamina C (Ácido ascórbico)-foi determinado por titulação com reagente de Tillman [2,6 diclorofenolindofenol (sal sódico) a $0,1 \%$ ]. Os resultados foram expressos em $\mathrm{mg} 100 \mathrm{~L}$ de ácido ascórbico por $100 \mathrm{~g}$ de amostra.

As médias das variáveis analisadas foram comparadas pelo teste de Tukey, em nível de 5\% de probabilidade. Os cálculos referentes às análises estatísticas foram executados, utilizando-se do software estatístico SAS (Statistical Analysis System, 2002).

\section{RESULTADOS E DISCUSSÃO}

A massa média dos frutos variou de 130,06 a 157,43g (Tabela 1). As maiores massas frescas de frutos foram obtidas por P. edulis (proveniente de semente), com 157,43 g de média, que não diferiram da combinação $P$. edulis /P. edulis, com 152,35 g, 
mas foram superiores às combinações de $P$. edulis /P. gibertii e P. edulis /P. mucronata, com 130,46 e $130,06 \mathrm{~g}$, respectivamente (Tabela 1). Esse resultado superou o encontrado por Greco et al. (2014), que avaliaram frutos em 32 genótipos de maracujazeiroazedo via seminífera, que variaram de 145,7 a 155,6 $\mathrm{g}$ e ficando abaixo dos encontrados por Cavichioli et al. (2011), que estudaram frutos de maracujazeiroamarelo enxertados em $P$. edulis, $P$. alata e $P$. gibertti , com 218,44; 223,04 e 199,68 g. Nogueira Filho et al. (2010b) não verificaram diferenças nas massas de frutos de maracujá-azedo enxertado sobre $P$. edulis, $P$. gibertii e $P$. mucronata com média de $156 \mathrm{~g}$. Neste trabalho, a massa fresca dos frutos foi significativamente menor que os tratamentos em que foram usadas as espécies $P$. gibertii e $P$. mucronata, indicando o efeito depressivo das espécies testadas como porta-enxertos sobre o peso médio dos frutos, sendo um importante caráter de seleção.

Os frutos com maiores diâmetros foram os obtidos em plantas sem enxertia, com 71,49 mm, não diferindo estatisticamente dos enxertados na combinação P. edulis/P. edulis com 70,02 mm (Tabela 1). Já os diâmetros dos frutos das plantas enxertadas com as combinações $P$. gibertti e $P$. mucronata diferiram entre si. Neste trabalho, os frutos das plantas enxertadas em espécies silvestres diferiram dos valores encontrados por Cavichioli et al. (2011), com 76,1 mm.

Comparando os diâmetros dos frutos de plantas enxertadas em diferentes porta-enxertos, verificou-se que não houve diferenças entre $P$. gibertii e $P$. mucronata, que diferiram da combinação $P$. edulis $/ P$. edulis. As diferenças observadas entre as espécies testadas como porta-enxertos podem ter ocorrido em razão de alguma falta de afinidade entre enxerto e porta-enxerto, uma vez que se trata de materiais de diferentes espécies. Nogueira Filho et al. (2010a) verificaram que plantas enxertadas em $P$. gibertii apresentaram menor vigor no campo, considerando que isso pode ter influenciado no comprimento e no diâmetro médio dos frutos. As menores dimensões, ou seja, menor comprimento médio e menor diâmetro médio observados nas plantas enxertadas podem explicar a menor massa descrita anteriormente para os tratamentos enxertados sobre $P$. gibertii e $P$. mucronata. A associação do menor tamanho de frutos ao menor vigor da planta pelo porta-enxerto necessita ser mais bem investigada, pois em outras espécies o nanismo causado por porta-enxertos menos vigorosos é associado à melhor qualidade dos frutos, inclusive quanto ao tamanho (MACHADO et al., 2013).
O comprimento médio dos frutos variou de 81,28 a $89,05 \mathrm{~mm}$ (Tabela 1). Esses valores ficaram próximos à variação nos comprimentos dos frutos de 77,0 a $81,1 \mathrm{~mm}$, observados por Freire et al. (2014a). De acordo com Cavichioli et al. (2011), o comprimento médio dos frutos variou de 99,2 mm na combinação $P$. edulis /P. gibertii a 109,1 mm em plantas provenientes de sementes, superior ao obtido por Greco et al. (2014), que variou de 80,67 a 95,32 $\mathrm{mm}$, dentro da faixa encontrada por Cavichioli et al. (2011), com 89,0 a 94,6 mm.

A relação entre o comprimento e o diâmetro (CF/DF) é utilizada para avaliar o formato dos frutos, considerando-se o valor igual a um para fruto redondo e maior, para fruto ovalado (GRECO et al. 2014). A relação $C F / D F$ verificada neste trabalho foi superior a um para frutos de todas as combinações e P. edulis (provenientes de semente), sendo, portanto, os frutos essencialmente oblongos ou ovalados (Tabela 1).

Os maiores comprimentos dos frutos foram obtidos em plantas provenientes de sementes e da combinação $P$. edulis / P. edulis, diferindo dos tratamentos enxertados com espécies silvestres $(\mathrm{P}<0,05)$. Os comprimentos dos frutos obtidos de plantas enxertadas em $P$. gibertii e $P$. mucronata apresentaram médias menores que os provenientes de semente, e resultado igual foi encontrado por Cavichioli et al. (2011). Comparando-se os três porta-enxertos, verificou-se que frutos obtidos de $P$. edulis /P. edulis foram maiores que de $P$. edulis /P. gibertii e P. edulis /P. mucronata. Diferenças na massa e nas dimensões de frutos em diversos relatos podem decorrer de fatores genéticos e ambientais, que variam entre experimentos e locais. No caso deste trabalho, foram verificadas diferenças na massa e nas dimensões com a utilização dos porta-enxertos, indicando que esse caráter é importante no processo de seleção.

Em geral, os frutos das plantas enxertadas foram menos pesados, menores no comprimento e largura, porém tendendo a ser mais oblongos que redondos, com menos polpa, possivelmente ao menor vigor das plantas silvestres de passifloras usadas como porta-enxertos. Analisando o diâmetro do caule a $5 \mathrm{~cm}$ do colo das plantas enxertadas, observou-se que, aos 120 dias após o transplante, plantas de $P$. edulis (não enxertado) apresentaram os maiores diâmetros de caule, com 11,09 mm, diferindo de plantas enxertadas em $P$. edulis, $P$. gibertti e $P$. mucronata com 7,61; 6,09 e 7,28 mm, respectivamente. Verificou-se que as espécies $P$. 
gibertii e P. mucronata foram as menos vigorosas. Comparando-se as três espécies usadas como porta-enxerto, verifica-se que as plantas sobre $P$. edulis tiveram o melhor desempenho. Admitindo-se que o diâmetro da planta é um indicativo de vigor (CAVICHIOLI et al., 2011), pode-se dizer que plantas de $P$. edulis enxertadas em porta-enxerto da mesma espécie são mais vigorosas. Cavichioli et al. (2011) verificaram que plantas enxertadas são menos vigorosas que as não enxertadas.

Os valores de espessura de casca não foram influenciados significativamente pelos tratamentos (Tabela 1); entretanto, foram inferiores quando comparados aos obtidos por outros autores. Krause et al. (2012) observaram, em cultivares de maracujazeiro-amarelo com polinização artificial ou natural, espessuras de casca entre 6,4 e 7,0 mm. A espessura da casca é fator importante a ser notado por ser inversamente proporcional ao rendimento de suco (FERREIRA et al., 2010). O menor valor de espessura de casca foi observado nos frutos das combinações $P$. edulis /P. gibertii, que foi de 5,38 mm (Tabela 1).

Segundo Lúcio et al. (2013), a maior espessura de casca relacionou-se com menor rendimento de suco, característica importante tanto para o mercado de frutos ao natural como para a indústria. De acordo com Freire et al. (2014a), frutos destinados à indústria precisam ter casca fina e possuir cavidade interna totalmente preenchida, a fim de conferir alto rendimento de suco.

$\mathrm{Na}$ porcentagem de rendimento (polpa/ fruto), foram encontrados frutos obtidos em plantas provenientes de sementes com 56,63\% contra $61,86 \%$ em plantas enxertadas em $P$. edulis e $57,57 \%$, $57,51 \%$ em plantas enxertadas em $P$. gibertii e $P$. mucronata, respectivamente. Já diversos autores relataram rendimento de polpa inferior ao encontrado neste estudo, com 35,9\% e 45,0\% (FREIRE et al., 2014a). Alves et al. (2012) relataram uma relação entre diâmetro e peso dos frutos e o rendimento de polpa.

Para a coloração do suco dos frutos, observaram-se diferenças significativas entre as combinações de $P$. edulis com os porta-enxertos e o $P$. edulis (proveniente de semente). Para valores de $\mathrm{L}$, que correspondem à luminosidade, os frutos das combinações de $P$. edulis $/ P$. edulis apresentaram o maior valor numérico, 47,66. O croma ficou entre 10,00 e 13,39, indicando que a saturação ou a quantidade de pigmento na polpa é baixa. $\mathrm{O}$ ângulo hue para a combinação $P$. edulis $/ P$. edulis e P. edulis (proveniente de semente) ficou situado dentro do primeiro quadrante (de zero a $90^{\circ}$ ), ou seja, cor vermelha a amarela, com valores 85,26 a 84,72 , determinando maior intensidade de vermelho, e as combinações de $P$. edulis /P. gibertii e $P$. edulis /P. mucronata, tendendo mais para a coloração amarela (Tabela 1). A coloração do suco pode ser um parâmetro utilizado como indicador da qualidade dos frutos destinados à industrialização, havendo preferência por frutos que possuem coloração amarelo-dourada estável (MANIWARA et al., 2014).

Na coloração da casca, não se observaram diferenças entre as combinações de $P$. edulis com os porta-enxertos e $P$. edulis (proveniente de semente). Para valores de L, que correspondem à luminosidade, os frutos de todas as combinações apresentaram valor numérico 70,82 a 71,94. O croma da combinação para $P$. edulis /P. mucronata ficou com valor numérico de 43,15, indicando que a saturação ou a quantidade de pigmento na casca é alta. O ângulo hue para todas as combinações e para $P$. edulis (não enxertado) ficou situado dentro do segundo quadrante $\left(>90^{\circ}\right)$, ou seja, coloração amarela, com valores 97,20 a 100,43, determinando maior intensidade de amarelo (Tabela 1). O incremento da cor amarela ocorre devido à degradação da clorofila, enquanto os pigmentos amarelos, alaranjados e vermelhos, pertencentes ao grupo dos carotenoides, são revelados ou sintetizados. Tais pigmentos são bastante comuns, e sua presença é um sinal por meio do qual o consumidor avalia a maturidade e a qualidade dos frutos (FREIRE et al., 2014b).

Os valores de acidez titulável e o teor de sólidos solúveis variaram de 4,43 a 5,11 g de ácido cítrico $100 \mathrm{~mL}^{-1}$ e 11,83 a $14,03{ }^{\circ}$ Brix, respectivamente (Tabela 1 ), sendo iguais aos resultados encontrados por Krause et al. (2012), cujos teores de sólidos solúveis variaram de 13,4 a $14,1 \%$, mas dentro da faixa aceitável para a indústria. Possivelmente, as diferenças em acidez e sólidos solúveis entre os tratamentos estejam influenciadas pela colheita e maturação desuniforme dos frutos devido à precocidade da floração das plantas enxertadas. Entretanto, a menor exigência em unidades térmicas pelo método da soma térmica (MATOS et al., 2014) e de acordo com Viera et al. (1999), considerando-se a temperatura mínima basal a $10^{\circ} \mathrm{C}$, e a máxima, a $36^{\circ} \mathrm{C}$., confirmouse a precocidade das plantas enxertadas. Sendo a combinação P.mucronata/P.edulis a de menor exigência, com 296.7 graus/dia, que corresponde ao tempo entre o plantio e primeira floração, seguida da 
combinação $P$. gibertti/P. edulis, P.edulis/P. edulis e $P$. edulis (não enxertado) com 673.80, 1.025 .59 e 1.717.62 graus/dia, respectivamente.

Com relação ao balanço entre açúcares e ácidos (teor de sólidos solúveis/acidez titulável), o valor mínimo obtido foi de 2,31, e o máximo, de 2,91 (Tabela 1), próximos daqueles encontrados por Cavichioli et al. (2011), que variaram de 2,8 a 3,5.

Em sucos integrais industrializados de maracujá, detectaram-se o teor de sólidos solúveis totais de 11,4 a $15,3^{\circ}$ brix, a acidez titulável de 2,7 a $3,9 \mathrm{~g}$ de ácido cítrico $100 \mathrm{~mL}^{-1} \mathrm{e}$ a relação brix/ acidez de 3,5 a 4,7 (GRECO et al., 2014). O teor de sólidos solúveis totais é um parâmetro que tem sido utilizado como indicador da qualidade dos frutos destinados à industrialização, havendo preferência por frutos com teores de sólidos solúveis superiores a $13^{\circ}$ brix (MANIWARA et al., 2014). Altos teores de ácidos no suco são importantes no que diz respeito ao processamento, já que permite maior flexibilidade na adição de açúcar, quando do preparo de bebidas prontas, além de conferir condições que dificultam a deterioração por microrganismos (FLORES et al., 2011). De acordo com o relatado anteriormente, verificou-se que os frutos provenientes das combinações de $P$. edulis com os porta-enxertos em condições de ambiente protegido apresentaram valores dentro dos padrões exigidos pela indústria de sucos, evidenciando o potencial de seu cultivo.

Os teores de vitamina $\mathrm{C}$ encontrados nos frutos de todas as combinações de $P$. edulis com os porta-enxertos e $P$. edulis Sims (proveniente de semente) ultrapassaram o valor de $20 \mathrm{mg}$ de ácido ascórbico $100 \mathrm{~g}^{-1}$ de polpa, que, segundo Santos et al. (2009), é normalmente observado em frutos de maracujazeiro-amarelo (Tabela 1). Houve diferenças nos teores de vitamina $C$ entre os tratamentos, pois $P$. edulis (proveniente de semente), com teor de 36,06 $\mathrm{mg} 100 \mathrm{~g}^{-1}$, foi significativamente superior às demais combinações (Tabela 1).
Os frutos das plantas enxertadas em condições de ambiente protegido estão dentro dos padrões de comercialização, de acordo com a norma de classificação do programa brasileiro de melhoria dos padrões comerciais e de embalagens de hortigranjeiros do maracujá-azedo (HORTIBRASIL, 2015), dentro do grupo de coloração amarela, classe tipo 3 (calibre de 65 até $75 \mathrm{~mm}$ ) apesar de apresentarem diferença na relação $\mathrm{CF} / \mathrm{DF}$ maiores que as plantas não enxertadas. 


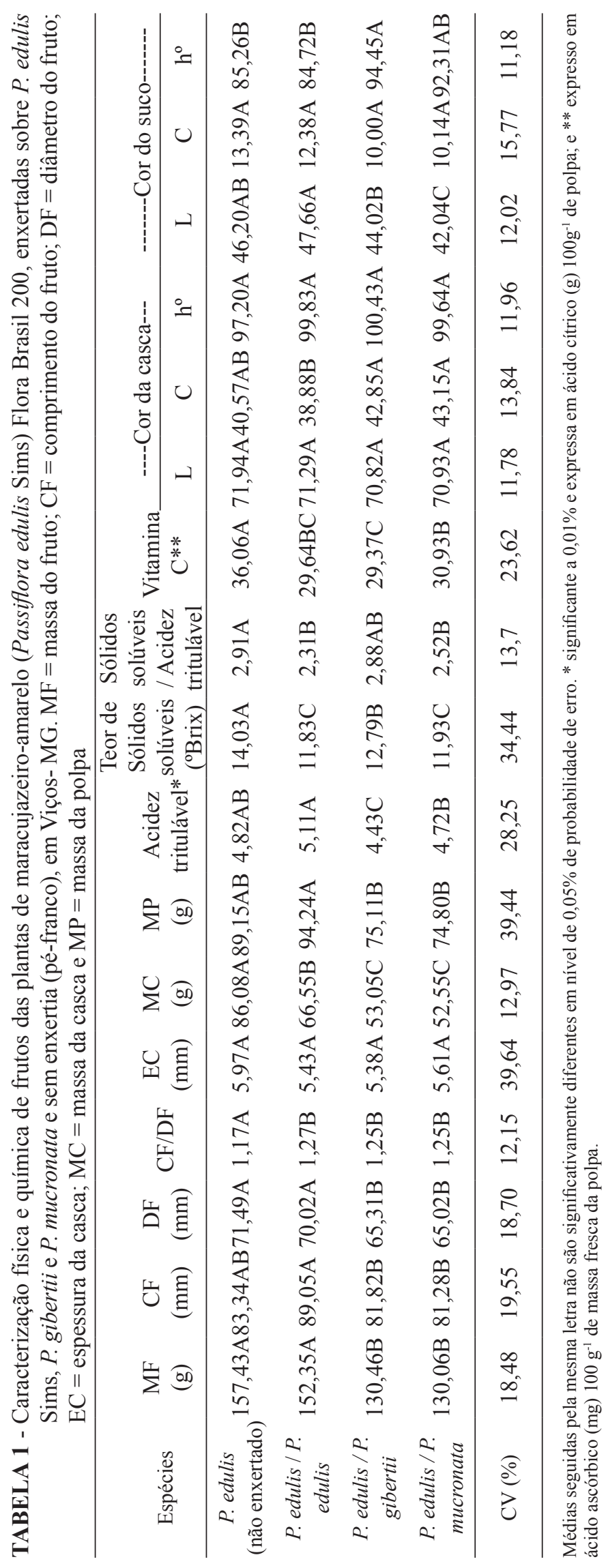




\section{CONCLUSÕES}

As plantas enxertadas e em ambiente protegido dão origem a frutos dentro dos padrões de comercialização, sem afetar o teor de sólidos solúveis, a acidez titulável, a coloração da casca e do suco e a vitamina $\mathrm{C}$.

\section{REFERÊNCIAS}

ALVES, R.R.; SALOMÃO, L.C.C.; SIQUEIRA, D.L.; CECON, P.R.; DA SILVA, D.F.P.Relações entre características físicas e químicas de frutos de maracujazeiro-doce cultivado em Viçosa-MG. Revista Brasileira de Fruticultura, Jaboticabal, v.34, n.2, p.619-623, 2012.

ATUCHA, A.; EMMET, B.; BAUERLE, T.L. Growth rate of fine root systems influences rootstock tolerance to replant disease. Plant and Soil, Dordrecht, v.376, n.1, p.337-346, 2014.

CAVICHIOLI, J. C.; CORREA, L. S.; GARCIA, M. J. M.; FISCHER, I. H. Desenvolvimento, produtividade e sobrevivência de maracujazeiroamarelo enxertado e cultivado em área com histórico de morte prematura de plantas. Revista Brasileira de Fruticultura, Jaboticabal, v.33, n.2, p.567-574, 2011.

FERREIRA, F.M., NEVES, L.G.; BRUCKNER, C.H.; VIANA, A.P.; CRUZ, C.D.; BARELLI, M.A.A.Formação de super-caracteres para seleção de famílias de maracujazeiro amarelo. Acta Scientiarum Agronomy, Maringá, v.2, n.32, p.247254, 2010.

FLORES, P.S.; DA SILVA, D.F.P.; BRUCKNER, C.H.; OLIVEIRA, S.P.; SALOMÃO, L.C.C. Caracterização físico-química de frutos de maracujazeiro amarelo provenientes da irradiação com raios gama. Ciência Rural, Santa Maria, v.41, n.11, p.1903-1906, 2011.

FREIRE, J.S.; CALVACANTE, L.; REBEQUI, A.M.; DIAS, T.J.; BREHM, M.A. SANTOS, J.B. Physical characteristics of fruit of yellow passion fruit produced in soil with bio-fertilizer, mulching and saline water. Idesia, Arica, v.32, n.1, p.71-78, $2014 a$.
FREIRE, J.S.; CALVACANTE, L.; REBEQUI, A.M.; DIAS, T.J.; BREHM, M.A. SANTOS, J.B. Quality of yellow passion fruit juice with cultivation using different organic sources and saline water. Idesia, Arica, v.32, n.1, p.79-87, 2014b.

GRECO, S.M.L.; PEIXOTO, J.R.; FERREIRA, L.M. Avaliação física, físico-química e estimativas de parâmetros genéticos de 32 genótipos de maracujazeiro-azedo cultivados no distrito federal. Bioscience Journal, Uberlândia, v.30, suppl.1, p.360-370, 2014.

HORTIBRASIL. Programa Brasileiro para Modernização da Agricultura. Maracujá-azedo: cartilha para classificação. Disponível em: $\leq$ www. hortibrasil.org.br>. Acesso em: 13 abr. 2015.

KRAUSE, W.; NEVES, L.G.; VIANA,A.P.;ARAÚJO, C.A.T.; FALEIRO, F.G. Produtividade e qualidade de frutos de cultivares de maracujazeiro-amarelo com ou sem polinização artificial. Pesquisa Agropecuária Brasileira, Brasilia, v.47, n.12, p.1737-1742, 2012.

LÚCIO, A. D.; STORCK, L.; KRAUSE, W.; GONÇALVES, R.Q.; NIED, A.H. Relações entre os caracteres de maracujazeiro-azedo. Ciencia Rural, Santa Maria, v.43, n.2, p.225-232, 2013.

MACHADO, B.D.; RUFATO, L.; BOGO, A.; KRETZCHMARL, A.A.; MARIO, A.E. Cultivares e porta-enxertos sobre o vigor de plantas de pereira europeias. Ciência Rural, Santa Maria, v.43, n.9, p.1542-1545, 2013.

MANIWARA, P.; NAKANO, K.; BOONYAKIAT, D.; OHASHI, S.; HIROI, M.; TOHYAMA, T. The use of visible and near infrared spectroscopy for evaluating passion fruit postharvest quality. Journal of Food Engineering, New York, v.143, p.33-43, 2014.

MATARAZZO, P.H.M.; SIQUEIRA, D.L.; SALOMÃO, L.C.C.; SILVA, D.F.P.CECON, P.R. Desenvolvimento dos frutos de lulo (Solanum quitoense LAM), em viçosa-MG. Revista Brasileira de Fruticultura, Jaboticabal, v.35, n.1, p.131-142, 2013. 
MATOS, V.A.T.; PIVETTA, F.P.; SOBRINHO, S.; TISSIANI, A.S.O.; PEREIRA, A.P.M.S.; RAMOS, F.T.; CAPELO. J.H. Temperaturas basais e exigência térmica para a maturação de caju. Bioscience Journal, Washington, v.30, n.4, p.969-977, 2014.

NOGUEIRA FILHO, G. C.; RONCATTO, G.; RUGGIERO, C.; DE OLIVEIRA, J. C.; BRAGA MALHEIROS, E. Desenvolvimento de plantas de maracujazeiro-amarelo produzidas por enxertia hipocotiledonar em cinco porta-enxertos de passifloras silvestres. Revista Brasileira de Fruticultura, Jaboticabal, v.32, n.2, p.527-534, 2010a.

NOGUEIRA FILHO, G. C.; RONCATTO, G.; RUGGIERO, C.; DE OLIVEIRA, J. C.; BRAGA MALHEIROS, E. Desenvolvimento e produção das plantas de maracujazeiro-amarelo produzidas por enxertia hipocotiledonar sobre seis porta-enxertos. Revista Brasileira de Fruticultura, Jaboticabal, v.32, n.2, p.535-543, 2010 b.

OCAMPO, J.; URREA, R.; WYCKHUYS, W.; SALAZAR, M. Exploración de la variabilidad genética del maracuyá (Passiflora edulis $\mathrm{f}$. flavicarpa Degener) como base para un programa de fitomejoramiento en Colombia. Acta agronómica, Palmira, v.62, n.4, p.352-360, 2013.
SANTOS, C. E. M.; BRUCKNER, C. H.; CRUZ, C. D.; SIQUEIRA, D. L.; PIMENTEL, L. D. Características físicas do maracujá-azedo em função do genótipo e massa do fruto. Revista Brasileira de Fruticultura, Jaboticabal, v.31, n.4, p.1102-1110, 2009.

SAS Institute. Release 9.0. Cary, 2002.

SILVA, A.; OLIVEIRA, E.J.; HADDAD, F.; LARANJEIRA, F.; JESUS, O.; OLIVEIRA, S.A.; CARVALHO, M.A.; FREITAS, P.X. Identification of passion fruit genotypes resistant to Fusarium oxysporum f. sp.Passiflorae. Tropical Plant Pathology, Brasília, v.38, n.3, p.236-242, 2013.

SILVA, J.O.C.; CREMASCO, J.P.G.; MATIAS, R.G.P.; SILVA, D.F.P.; HURTADO-SALAZAR, A.; BRUCKNER, C.H. Divergência genética entre populações de pessegueiro baseada em características da planta e do fruto. Ciência Rural, Santa Maria, v.44, n.10, p.1770-1775, 2014. 